
\title{
R Reserach S Suare \\ Prediction of Size of the COVID-19 Pandemic Using Wavelength Models: Cases of Turkey and World
}

Tevfik Bulut ( $\square$ buluttevfik@gmail.com )

Republic of Turkey Ministry of Industry and Technology https://orcid.org/0000-0002-3668-7436

Mustafa Çağrı Yıldız

Konya Training and Research Hospital

Keywords: Pandemic, COVID-19, Net Wavelength, Case Wavelength, Death Wavelength, Recovered Case Wavelength, Epidemic, Prevelance, Incidence, CDR, CFR

Posted Date: June 11th, 2020

DOI: https://doi.org/10.21203/rs.3.rs-34521/v1

License: (c) (i) This work is licensed under a Creative Commons Attribution 4.0 International License. Read Full License 


\section{Abstract}

The main purpose of the study is to predict the magnitude of the Covid- 19 pandemic by using epidemiological wavelength models in Turkey and at international level. Therefore, firstly, the first 36 days of wavelengths based on the number of daily coronavirus cases in Turkey were calculated. In addition, 114 countries were compared in terms of Covid-19 wavelengths considering the cumulative number of the pandemic cases occured at the end of the first 36 days for evaluation on an equal plane. In the last part of the study, the wavelengths of 185 countries were examined comparatively based on the cumulative number of cases at the end of the time frame from the first epidemic case until 2020-04-16 (including that date). According to the findings of wavelength obtained in Turkey, it was observed that case wavelength on 2020-04-11, death and recovered case wavelength on 2020-04-16, and net wavelength on 2020-03-26 reached its peak. China was the country having the highest wavelength of case, death, and recovered case wavelengths in 114 countries at the end of the first 36 days since the first case occurred. In that country, wavelengths of case, death and recovered case were 33.6, 23.5 and 30.7, respectively. The first three countries with the highest net wavelength at the end of the first 36 days were Serbia (36.5), Netherlands (33.5) and Portugal (30.3), respectively. On the other hand, the country having the highest case and death wavelengths among 185 countries in the time interval from the first case until the date of 2020-04-16 (including that date) was the USA, and case and death wavelengths were 39.7 and 30.7, respectively. The country with the highest recovered case wavelength was China (33.3). The first 3 countries with the highest wavelengths are Canada (51.4), England (45.0) and Serbia (39.2), respectively.

\section{Introduction}

SARS-CoV-2, which causes coronavirus disease (Covid-19), was first seen in Wuhan city of China in December 2019, and then spread to at least 187 countries and regions worldwide, causing an already ongoing pandemic $[9,10,11]$. While symptoms such as cough, fever and shortness of breath are frequently observed in Covid-19 infection, these symptoms may be accompanied by symptoms such as abdominal pain, fatigue, diarrhea, loss of taste and smell, abdominal pain [12]. The first symptoms after contact appear between 2 and 14 days, with an average of 5 days. Covid-19 spreads from person to person through coughing, sneezing, and speech. However, crowded areas increase this spreading process. Although many patients easily recovered, the infection rapidly progressed to viral pneumonia and multiple organ failure in patients with comorbidity [13,34]. Also, the coronavirus, which can survive for about 72 hours on surfaces, can be taken into the human body by touching these contaminated surfaces [14].

For the diagnosis firstly nasopharyngeal swab must be taken as a sample and the standard method of diagnosis is by real-time reverse transcription polymerase chain reaction (rRT-PCR) must be applied to the sample. If there is a high suspicion about Covid-19 infection and patient has some symptoms and risk factors Chest CT imaging may be helpful for diagnosis, but guidelines do not recommend using Chest CT for routine screening of patients $[15,16]$. To prevent Covid-19 infection, we must take some meaures like hand washing almost 20 seconds, maintaining physical distance from others (especially 
from those with symptoms) and not touching to the face with unwashed hands. Since a vaccine suitable for covid-19 and a specific antiviral therapy cannot be developed, parameters such as symptomatic therapy, supportive therapy and isolation are included in the management of the disease [17]. The supportive treatment offered to patients includes liquid electrolyte therapy, oxygen supplementation and supporting other vital organs and treatment mechanisms are used according to the severity of the disease $[18,19,20]$. Extracorporeal membrane oxygenation (ECMO) has been used in the treatment of respiratory failure and its effectiveness is not yet fully understood. It is known that personal hygiene and wellness habits affect immunity positively. Supportive treatments are thought to be effective in the early stages of the infection and mild symptoms [21,22].

There is no specific treatment method for coronavirus disease as of April 2020. Also, it is not enough information about angiotensin converting enzyme inhibitors and low-molecular-weight heparin is recommended as a treatment that prevents blood clotting. Treatment appears to be effective in patients with severe coronavirus showing signs of coagulopathy [23]. Like the symptoms of Covid-19, the prognosis of the disease differs from person to person. While patients with mild symptoms improve within 2 weeks, the duration of hospitalization and treatment of patients with moderate to severe symptoms varies between 3-6 weeks [24].

Children are sensitive to the disease, but they experience the infection with milder symptoms than adults. That is, the risk of death is less than $0.5 \%$ in those younger than 50 years, while it is more than $8 \%$ in those older than 70 years [25]. Many patients who died due to Covid-19 have hypertension, diabetes mellitus and cardiovascular disease. It was reported by the Istituto Superiore di Sanità that out of $8.8 \%$ of deaths where medical charts were available for review, $97.2 \%$ of sampled patients had at least one comorbidity which had the average patient with 2.7 diseases [26].

The availability of medical resources can also affect mortality in the socioeconomic situation. Therefore, estimates of mortality from disease differ due to both regional differences and methodological difficulties [27]. The measurement of mortality generally varies by region and time. Mortality is influenced by many factors such as the quality of healthcare and ease of access to healthcare, age, sex and time since the onset of the disease [28]. Statistical parameters such as infection-induced death (IFR), which reflects the percentage of infected individuals who have been diagnosed or undiagnosed, and the casedeath rate (CFR), representing the percentage of those who die from a disease diagnosed, are used in mortality calculations because they are independent of time [29].

In the study, in first place, epidemiological descriptive statistics of Covid-19 pandemic in Turkey were examined. In addition, it was predicted the first 36-day epidemiological wavelengths to measure the magnitude of the epidemic in Turkey. Furthermore, in order to make evaluations on the same plane, the wavelengths of countries at the end of the first 36 days in which coronavirus cases emerged were analyzed comparatively at the international level. At the same time, the wavelengths of countries have been handled comparatively at the international level at the end of the time interval in which passed from the date in which the first coronavirus case was observed until 2020-04-16 (including that date). 


\section{Methodology}

In the study, it was aimed to estimate comparatively the magnitude of the Covid-19 pandemic using the wavelength models in Turkey as well as at the international level. For this reason, in this section, the sources of data sets used in the research, the presentation of the findings, epidemiological rates, and the theoretical framework of the wavelength models are included.

Two different data sets were used in the research. The first data set includes Covid-19 cases in Turkey. The number of cases in this data set was obtained from web site https://Covid19.saglik.gov.tr. This web site, which is one of the web sites of Republic of Turkey Ministry of Health, was established to provide information to the public about Covid-19 cases [4]. The reason for getting data from this site is that the data set contains the number of daily Covid-19 tests and cases. That is to say, the number of Covid-19 cases and tests is available both cumulatively and daily on the web site.

The other data set covers international Covid-19 cases. The data set was obtained from the Human Data Exchange (HDX), one of the web sites belonging to United Nations Office for the Coordination of Humanitarian Affairs [3]. On this website, coronavirus data sets are independent from each other, and there are three different data sets, which are confirmed, death and recovered case data set. These data sets received from this web site have csv extension. Datasets were combined using data mining techniques. Microsoft Excel 2016 and mainly R programming language were used in data mining and analysis phase $[1,2]$. Since there are duplicate records in time series in data sets, these records are reduced to unique time series within each country. The number of cases in the data set follows a cumulative course as in the source site, and the data set covers the coronavirus cases of 185 countries.

In first place, the first 36 days of epidemiological wavelengths were estimated for Turkey, depending on the number of daily coronavirus cases until the date of 2020-04-16 (including that date). Later, wavelengths were calculated based on cumulative case numbers in each of the world countries at the end of the first 36 days in order to be evaluated on the same plane with Turkey. To this purpose, the number of cumulative cases at the end of the first 36 days at which passed from the first coronavirus case until the date 2020-04-16 (including that date) were taken as data.

On the other hand, the mentioned 36-day time limit were not sought to see the current wavelengths at international level and to make comparisons. In other words, since the dates when the coronavirus pandemic appeared vary between countries, the number of days from the date of the first case to the date of 2020-04-16 (including that date) may decrease below 36 or exceed 36 . Here, the cumulative case numbers of world countries were taken as data on 2020-04-16 (including that date).

\subsection{Epidemiological Rates}

In this section, epidemiological rates used in the study are discussed. One of the epidemiological rates utilized to measure rate of emergence of the disease is prevalence. Prevalence is expressed as proportion of a given population influenced by a risk factor or a disease at a given time. It is obtained by comparing 
the number of people having the condition with the total number of people studied, and is often stated as a percentage, number of cases per 10,000 people, or a fraction [30]. Within the scope of the study, the number of approved cumulative cases and cumulative Covid-19 tests were used to calculate prevalence. Prevalence was calculated with the help of equation (1). The number of cumulative cases was included in numerator of the equation, and the number of cumulative tests was included in its denominator. The product coefficient was taken as 100 .

Prevalence $=\frac{\text { The number of cumulative cases }}{\text { The number of cumulative tests }} \times 100$

The other of the epidemiological rates utilized to measure rate of emergence of the disease is incidence. Incidence is desribed as the probability of new cases occurring in a population having a specific medical condition in a given time period [31]. In calculating incidence, the number of daily Covid-19 tests and cases were used. Incidence was calculated using equation (2). The number of daily cases was included in numerator of the equality, and the number of daily Covid-19 tests was included in denominator of the equality.

Incidence $=\frac{\text { The number of daily cases }}{\text { The number of daily Covid-19 tests }} \times 100$

The first of the epidemiological death measures is crude death rate (CDR). CDR is the number of deaths observed in populaton of a certain geographic area in a specific time. It can be multiplied by 1,000 or $100,000[32,37]$. CDR was calculated with the help of equation (3) in the study. The reason for the multiplication coefficient to be taken as $1,000,000$ in the equation is that the ease of interpretation is desired.

$C D R=\frac{\text { The number of daily cases }}{\text { Mid-interval population }} \times 1,000,000$

(3)

The other of the epidemiological death measures is a case fatality rate (CFR), which is sometimes described as case fatality risk. CFR is defined as the proportion of deaths among those diagnosed with a particular disease in a certain time interval. The multiplication coefficient of CFR is usually 100 , and is often used to measure disease severity [33]. CFR, which is a more sensitive measure compared to CDR, was calculated with the help of equation (4).

CFR $=\frac{\text { The number of daily deaths }}{\text { The number of daily cases }} \times 100$

(4)

\subsection{Theoretical Framework of Wavelength Models}

In this section, theoretical framework of epidemiological wavelength models that predict magnitude of outbreaks developed by Tevfik Bulut in 2020 is discussed [5]. Wavelength models focus on output 
variables that are easy to understand and apply. Wavelength models consist of 4 similar equations based on the number of cases and which must be calculated respectively:
1. Case wavelength
2. Death wavelength
3. Recovered case wavelength
4. Net wavelength

In order to calculate the said net wavelength, case wavelength, death wavelength and recovered case wavelength must first be calculated, and then recovered case wavelength must be subtracted from the sum of case wavelength and death wavelength. The parameters used in wavelength model equations are given in Table 1.

Table 1: Parameters of Wavelength Models

\begin{tabular}{|c|c|c|c|}
\hline Parameters & Symbol & Parameters & Symbol \\
\hline Approved cumulative total number of cases & $C_{C}$ & Wavelength & $W$ \\
\hline Approved cumulative total death number of cases & $d_{C}$ & Case wavelength & $W_{c}$ \\
\hline Approved cumulative total recovered number of cases & $r_{c}$ & Death wavelength & $W_{d}$ \\
\hline Number of days since the first case was announced & $t_{c}$ & $\begin{array}{l}\text { Recovered case } \\
\text { wavelength }\end{array}$ & $W_{r}$ \\
\hline $\begin{array}{l}\text { The ratio of within the total day of the year of the number of days passed since the first case } \\
\text { announced }\end{array}$ & $t_{r}=\frac{t_{c}}{365,25}$ & Net wavelength & $W_{\text {net }}$ \\
\hline
\end{tabular}

While calculating the wavelengths in the models, a path could be drawn as follows: A wavelength could also be calculated from the active case numbers obtained after subtracting deaths and recovered cases from the number of cases. However, this has not been done because the aim is to seek and monitor individual wavelengths of coronavirus cases in the context of confirmed cases, deaths, and recovered cases.

On the other hand, population data could be included in the equations used in the wavelength models. However, this has not been done done. The reason for this is that population data is not a realized output variable and the developed models aim to present the current situation in a valid, reliable and easy-toapply manner.

The equations used in the wavelength models are as follows: Case wavelength in equal (5), death wavelength in equality (6), recovered case wavelength in equality (7), and lastly in net wavelength equation (8). 


$$
\begin{aligned}
& W_{c}=\ln \left[\left(c_{c}\right)^{3} x\left(1-t_{r}\right)^{2}+1\right] \\
& W_{d}=\ln \left[\left(d_{c}\right)^{3} x\left(1-t_{r}\right)^{2}+1\right] \\
& W_{r}=\ln \left[\left(r_{c}\right)^{3} x\left(1-t_{r}\right)^{2}+1\right] \\
& W_{n e t}=W_{c}+W_{d}-W_{r}
\end{aligned}
$$

In order to reveal the magnitude of the epidemic, $W_{c}$ is calculated with the help of equation (5) in the first place. The higher the $W_{C}$, the greater the magnitude and the effect level of the epidemic in the population. The high $W_{d}$ shows that the epidemic has a lethal effect on the population. On the other hand, $W_{r} s$ rising trend is a situation that should be interpreted positively. As a result, $W_{\text {net }}$ consists of $W_{c}, W_{d}, W_{r}$ equations. As $W_{\text {net }}$ rises, the level of negative impact of the epidemic in the population means so high.

\section{Findings}

In this section, it was firstly given to epidemiological descriptive statistics derived from coronavirus cases in Turkey. After descriptive statistics, the first 36 days of epidemiological wavelengths of Covidien-19 outbreak in Turkey were evaluated. Besides, the wavelengths were analyzed comparatively at the international level based on the cumulative case numbers at the end of the first 36 days. In the end, the wavelengths were examined comparatively at the international level based on the cumulative case numbers at the end of the time period until 2020-04-16 (including that date) without the first 36-day limit. The way followed in the presentation of the findings at the international level is as follows: According to the wavelength models, the first 10 countries with the highest wavelength are included in figures.

\subsection{Epidemiological Descriptive Statistics}

Under this title, the course of coronavirus cases in Turkey were initially examined. The epidemiological descriptive statistics obtained are given in Figure 1. The findings show that there were sharp increases in the number of confirmed cases, deaths, and recovered cases in general until 2020-04-11, there was a rapid decline the day after that date, and then entered an upward trend. Another striking finding here was that the number of recovered cases started to be well above the number of deaths and confirmed cases.

Incidence, prevalence, CFR and CDR values of Covid-19 cases in Turkey are given in Figure 2. The population of Turkey in 2019, released by Turkish Statistical Institute on 2020-02-04, was 83,154,997 [36]. That data was used to calculate CDR. Since there was no recorded test information for the time series before 2020-03-21, the number of cases in the time series before that date is not included in Figure 2 . From the findings obtained, it was observed that an upward trend in prevalence continued until 2020-0329 , followed by a stable course. It was seen that prevalence started to lose momentum similar to incidence on 2020-04-11. In Figure 2, a sharp decrease was observed in incidence after peaking. It was seen that incidence fell below prevalence after 2020-04-11. On the other hand, it was observed that CFR reached its peak on 2020-03-21, followed by a fluctuating downtrend. However, it was observed that CDR displayed a steady rise in general, and peaked on 2020-04-16. 


\subsection{Epidemiological Wavelengths}

In the presentation of findings obtained from the wavelength (W) models, firstly, daily wavelengths of coronavirus cases in Turkey were examined. The findings are given in Figure 3. In calculating of daily wavelengths, it was taken as $t_{c}=1, c_{c}$ : the number of daily confirmed cases, $d_{c}$ : the number of daily deaths, and $r_{c}$ : the number of daily recovered cases.

It was observed that daily case wavelengths $\left(\mathrm{W}_{\mathrm{c}} \mathrm{s}\right)$ in Turkey indicated an upward trend, but an increase in decreasing direction according to Figure 3 . The increase trend in death wavelengths $\left(W_{d} s\right)$ was generally below case $\left(W_{c}\right)$, recovered case $\left(W_{r}\right)$ and net wavelength $\left(W_{\text {net }}\right)$ trend. It was observed that $W_{r}$ increased sharply after 2020-03-26, and rose steadily. On the other hand, it was observed that $W_{\text {net }}$ reached its peak on 2020-03-26, and followed a generally declining trend after that date.

Wavelengths in the world at the end of the first 36-day time frame until 2020-04-16 (including that date) in Turkey has been shown in Figure 4 . Wavelength $(W)$ findings consist of case $\left(W_{c}\right)$, death $\left(W_{d}\right)$, recovered case $\left(W_{r}\right)$ and net wavelength $\left(W_{\text {net }}\right)$ findings of 114 countries in Figure 4 . In the figure, $y$ axis shows the wavelengths (Ws), and $x$ axis shows the number of countries. It was seen from the findings that $W_{c} s$ had a higher trend than other wavelengths in general. It was observed that the highest wavelength was derived from $\mathrm{W}_{\text {net }}$.

Wavelengths of countries in the world at the end of the first 36-day time frame until 2020-04-16 (including that date) in Turkey has been given in Figure 5. The first 10 countries with the highest wavelengths among 114 countries are presented in Figure 5 . The findings show that the country having the highest $W_{c}$ was China with 33.6 points, followed by Turkey (33.2) and Iran (30.4), respectively. The country with the highest $\mathrm{W}_{\mathrm{c}}$ was observed to be China with 23.5 points as in $\mathrm{W}_{\mathrm{c}}$. China was followed by Iran and Turkey, respectively. On the other hand, the country with the highest $W_{r}$, as in previous wavelengths, was China with 30.7 points. China was followed by Iran and Turkey, respectively. Finally, it was observed that the country with the highest $W_{\text {net }}$ was Serbia with 36.5 points, followed by Netherlands (33.5) and Portugal (30.3), respectively.

Wavelengths in the period from first epidemic case observed in the world until 2020-04-16 (including that date) have been given in Figure 6 . Wavelength findings cover the ones of 185 countries. In the figure, $y$ axis shows wavelengths $(W)$, and $x$ axis shows the number of countries. The findings show that the highest $W$ values in general was in $W_{\text {net, }}$, followed by $W_{c}$ and $W_{r}$, respectively. This means that the magnitude of the epidemic gained width and depth when compared to the first 36-day wavelength.

The first 10 countries with the highest wavelengths in 185 countries in the period from first epidemic case seen in the world until 2020-04-16 (including that date) have been given in Figure 7. Findings point out that the country having the highest $W_{c}$ was the USA with 39.7 points, followed by Spain (35.9) and Italy (35.6), respectively. The country with the highest $W_{d}$ was the USA with 30.7 points, as in $W_{c}$, followed by 
Italy and Spain, respectively. On the other hand, the country having the highest $\mathrm{W}_{\mathrm{r}}$ is China with 33.3 points, followed by Germany and Spain, respectively. However, it was observed that the country having the highest $W_{\text {net }}$ is Canada with 51.4 points, followed by England (45.0) and Serbia (39.2), respectively.

\section{Conclusion And Discussion}

In this study, It is aimed to be predicted the magnitude of the Covid-19 outbreak by using epidemiological wavelength models in Turkey and at international level. In this way, it is intended to contribute to decisionmakers to make more reliable decisions and to follow the epidemic process more easily.

To begin with, the first 36 days of wavelengths were predicted in Turkey until 2020-04-16 (including that date). It was observed that daily case wavelengths in Turkey demonstrated an upward trend, but an increase in decreasing direction. The increase trend in death wavelengths was below case, recovered case and net wavelength trend in general. It was monitored that recovered case wavelength increased sharply after 2020-03-26, and rose steadily. On the other hand, net wavelength reached its peak on 2020-03-26, and lost momentum after that date in general. It can be argued that measures such as social distancing, self-isolation and quarantine taken to prevent spread of the epidemic were effective on that decrease in $\mathrm{W}_{\text {net }}$. Some of these measures are as follows: It is believed that the curfew imposed on individuals aged 65 and over and individuals with chronic illnesses, which was taken by Ministry of Interior on 2020-03-21, is considered to be effective [6]. Besides, a curfew was imposed on 2020-04-03 by Ministry of Interior for individuals aged 20 and under, who are seen as the carriers of the Covid-19 virus in the high-risk group. Another measure is the inter-provincial travel restrictions, which are thought to be effective in this decline [7]. In addition, as a result of the decision taken jointly by Ministry of Health and Ministry of Transport and Infrastructure, measures taken for free distribution of mask distribution across the country through an online platform are also thought to play an important role in the decrease in net wavelength [8]. Furthermore, With the decision of the Ministry of Health, citizens coming from abroad were quarantined for 14 days in hospitals or other designated places [35].

The first 3 countries having the highest case wavelength are China (33.6), Turkey (33.2), Iran (30.4) in 114 countries at the end of the first 36-day period. The country with the highest death wavelength was observed to be China with 23.5 points as in case wavelength. That country was followed by Iran and Turkey, respectively. On the other hand, the highest country in recovered case wavelength is China (30.7), as in previous wavelengths, followed by Iran and Turkey, respectively. Lastly, the country having the highest net wavelength was Serbia (36.5), followed by Netherlands (33.5) and Portugal (30.3), respectively.

It was observed that the country having the highest wavelength in 185 countries was USA (39.7) in the time period until 2020-04-16 (including that date) regardless of the first 36 days. That country was followed by Spain (35.9) and Italy (35.6), respectively. The country with the highest death wavelength is the USA (30.7), as in case wavelength, followed by Italy and Spain, respectively. On the other hand, the country with the highest recovered case wavelength was China (33.3), followed by Germany and Spain, 
respectively. However, the first 3 countries with the highest net wavelength are Canada (51.4), England (45) and Serbia (39.2), respectively.

In the study, the epidemic process can be monitored more closely by revealing both daily and cumulative wavelengths from the day when the first case of Covid-19 was observed in each country. Thus, decision makers can make faster and more reliable decisions by managing the epidemic's development process better.

\section{Limitations}

The wavelength study is a study to reveal the current situation. Therefore, the wavelength findings obtained are not forecastable for the future. However, it is always possible to make a forecast study with different methods by accepting the findings obtained as input. On the other hand, the measures taken by countries against the coronavirus pandemic except Turkey is not known exactly. Therefore, the wavelength findings of these countries could not be handled in depth in the study. If the measures taken by countries against the disease are known, wavelength findings will be thoroughly evaluated.

\section{Declarations}

Competing interests: The authors declare no competing interests

\section{References}

1. Microsoft Corporation. (2018). Microsoft Excel. Retrieved from https://office.microsoft.com/excel

2. R Core Team. (2018). "R: A language and environment for statistical computing. R Foundation for Statistical Computing". Vienna, Austria. URL: https://www.r-project.org.

3. United Nations Office for the Coordination of Humanitarian Affairs (OCHA), The Humanitarian Data Exchange (HDX). URL: https://data.humdata.org. Access Date: April 17, 2020.

4. Republic of Turkey Ministry of Health. COVID-19 Information Platform. URL: https://Covid19.saglik.gov.tr. Access Date: April 17, 2020.

5. Bulut, T. "New Epidemiological Model Suggestions Revealing Size of Epidemics Based on the COVID19 Pandemic Example: Wavelength Models”. medRxiv; 2020. DOI: 10.1101/2020.04.07.20056432.

6. Republic of Turkey Ministry of Interior. "Curfew Circular on Those 65 and Over and Chronic Diseases Dated 2020-03-21". URL: https://www.icisleri.gov.tr/65-yas-ve-ustu-ile-kronik-rahatsizligi-olanlarasokaga-cikma-yasagi-genelgesi. Access Date: April 20, 2020.

7. Republic of Turkey Ministry of Interior. "City Entry / Exit Notices and Age Restriction Circular (Annex Circular) Dated 2020-04-13". URL: https://www.icisleri.gov.tr/sehir-giriscikis-tebirleri-ve-yassinirlamasi. Access Date: April 20, 2020.

8. Republic of Turkey Ministry of Health and Republic of Turkey Ministry of Transport and Infrastructure. “Free Mask Distribution”. URL: https://basvuru.turkiye.gov.tr. Access Date: April 20, 
2020.

9. Mayo Clinic. "Coronavirus disease 2019 (COVID-19)-Symptoms and causes". Access Date: April 14, 2020.

10. Hui, D. S., I Azhar, E., Madani, T. A., Ntoumi, F., Kock, R., Dar, O., Ippolito, G., Mchugh, T. D., Memish, Z. A., Drosten, C., Zumla, A., \& Petersen, E. (2020). The continuing 2019-nCoV epidemic threat of novel coronaviruses to global health - The latest 2019 novel coronavirus outbreak in Wuhan, China. International journal of infectious diseases: IJID: official publication of the International Society for Infectious Diseases, 91, 264-266. https://doi.org/10.1016/j.ijid.2020.01.009. PMID: 31953166.

11. World Health Organization (WHO). Press Release."WHO Director-General's opening remarks at the media briefing on COVID-19". Access Date: March 12, 2020.

12. Hopkins, Claire. "Loss of sense of smell as marker of COVID-19 infection". Ear, Nose and Throat surgery body of United Kingdom. URL: https://www.entuk.org/loss-sense-smell-marker-Covid-19infection. Access Date: March 28, 2020.

13. Velavan, T. P.; Meyer, C. G. (March 2020). "The COVID-19 epidemic". Tropical Medicine \& International Health. n/a(n/a): 278-80. DOI:1111/tmi.13383. PMID 32052514.

14. National Institutes of Health (NIH). "New coronavirus stable for hours on surfaces". URL: https://www.nih.gov/news-events/news-releases/new-coronavirus-stable-hours-surfaces. Access Date: March 23, 2020.

15. Centers for Disease Control and Prevention (CDC). "Interim Guidelines for Collecting, Handling, and Testing Clinical Specimens from Persons for Coronavirus Disease 2019 (COVID-19)". Access Date: March 26, 2020.

16. American College of Radiology. "ACR Recommendations for the use of Chest Radiography and Computed Tomography (CT) for Suspected COVID-19 Infection". Access Date: March 22, 2020.

17. Centers for Disease Control and Prevention (CDC). "How to Protect Yourself \& Others". Access Date: April 8, 2020.

18. Fisher D, Heymann D (February 2020). "Q\&A: The novel coronavirus outbreak causing COVID-19". BMC Medicine. 18 (1): 57. DOI:10.1186/s12916-020-01533-w. PMC 7047369. PMID 32106852.

19. Kui L, Fang YY, Deng Y, Liu W, Wang MF, Ma JP, et al. (February 2020). "Clinical characteristics of novel coronavirus cases in tertiary hospitals in Hubei Province". Chinese Medical Journal: 1. DOI: 10.1097/CM9.0000000000000744. PMID 32044814.

20. Wang T, Du Z, Zhu F, Cao Z, An Y, Gao Y, Jiang B (March 2020). "Comorbidities and multi-organ injuries in the treatment of COVID-19". Lancet. Elsevier BV. 395 (10228): e52. DOI:10.1016/s01406736(20)30558-4. PMID 32171074.

21. Wang, Yixuan; Wang, Yuyi; Chen, Yan; Qin, Qingsong. "Unique epidemiological and clinical features of the emerging 2019 novel coronavirus pneumonia (COVID-19) implicate special control measures". Journal of Medical Virology. n/a (n/a). DOI:10.1002/jmv.25748. ISSN 1096-9071.

22. Wang T, Du Z, Zhu F, Cao Z, An Y, Gao Y, Jiang B (March 2020). "Comorbidities and multi-organ injuries in the treatment of COVID-19". Lancet. Elsevier BV. 395 (10228): e52. DOI: 10.1016/s0140- 
6736(20)30558-4. PMID 32171074.

23. Tang, Ning; Bai, Huan; Chen, Xing; Gong, Jiale; Li, Dengju; Sun, Ziyong. "Anticoagulant treatment is associated with decreased mortality in severe coronavirus disease 2019 patients with coagulopathy". Journal of Thrombosis and Haemostasis. n/a (n/a). DOI:10.1111/jth.14817. ISSN 1538-7836.

24. World Health Organization (WHO). "Report of the WHO-China Joint Mission on Coronavirus Disease 2019 (COVID-19)". Access Date: February 29 , 2020.

25. Castagnoli, R; Votto, M; Licari, A (April 2020). "Severe Acute Respiratory Syndrome Coronavirus 2 (SARS-CoV-2) Infection in Children and Adolescents A Systematic Review". JAMA Pediatrics. DOI: 10.1001/jamapediatrics.2020.1467.

26. Palmieri L, Andrianou X, Barbariol P, Bella A, Bellino S, Benelli E, et al. (3 April 2020). Characteristics of COVID-19 patients dying in Italy. Report. Istituto Superiore di Sanità. Access Date: April 3, 2020.

27. Ji Y, Ma Z, Peppelenbosch MP, Pan Q (February 2020). "Potential association between COVID-19 mortality and health-care resource availability". Lancet Global Health. 8 (4): e480. DOI:10.1016/S2214-109X(20)30068-1. PMID 32109372.

28. Ritchie, Hannah and Roser, Max (25 March 2020). Chivers, Tom (ed.). "What do we know about the risk of dying from COVID-19?". URL: https://ourworldindata.org/Covid-mortality-risk. Access Date: March 28, 2020.

29. "What do we know about the risk of dying from COVID-19?". Our World in Data. URL:

https://ourworldindata.org/Covid-mortality-risk. Access Date: March 8, 2020.

30. William C. Shiel Jr., MD, FACP, FACR. "Medical Definition of Prevalence". URL: https://www.medicinenet.com/script/main/art.asp?articlekey=11697. Access Date: December 3, 2019.

31. Louise-Anne McNutt and Allison Krug. "Incidence". Epidemiology. Encyclopaedia Britannica. URL: https://www.britannica.com/science/incidence-epidemiology. Access Date: April 3, 2020.

32. Statistical Notes for Health Planners. No: 3. Mortality. Kleinman, J. C. February 1977. 16 pp. (HRA) 77-1237.

33. Rebecca A. Harrington. “Case fatality rate”. Encyclopedia Britannica. URL: https://www.britannica.com/science/case-fatality-rate. Access Date: April 4, 2020.

34. World Health Organization (WHO). "How does COVID-19 spread”. URL: https://www.who.int/newsroom/q-a-detail/q-a-coronaviruses. Access Date: April 26, 2020.

35. Republic of Turkey Ministry of Health. "Monitoring (Quarantine) Rules For New Coronavirus Virus at Home”. URL: https://acilafet.saglik.gov.tr/TR,64512/korona.html. Access Date: April 17, 2020.

36. Turkish Statistical Institute. URL: http://www.tuik.gov.tr/PreHaberBultenleri.do?id=33705. Access Date: April 26, 2020.

37. Handbook of Vital Statistics Systems and Methods, Volume 1: Legal, Organisational and Technical Aspects, United Nations Studies in Methods, Glossary, Series F, No. 35, United Nations, New York 1991. 
Figures
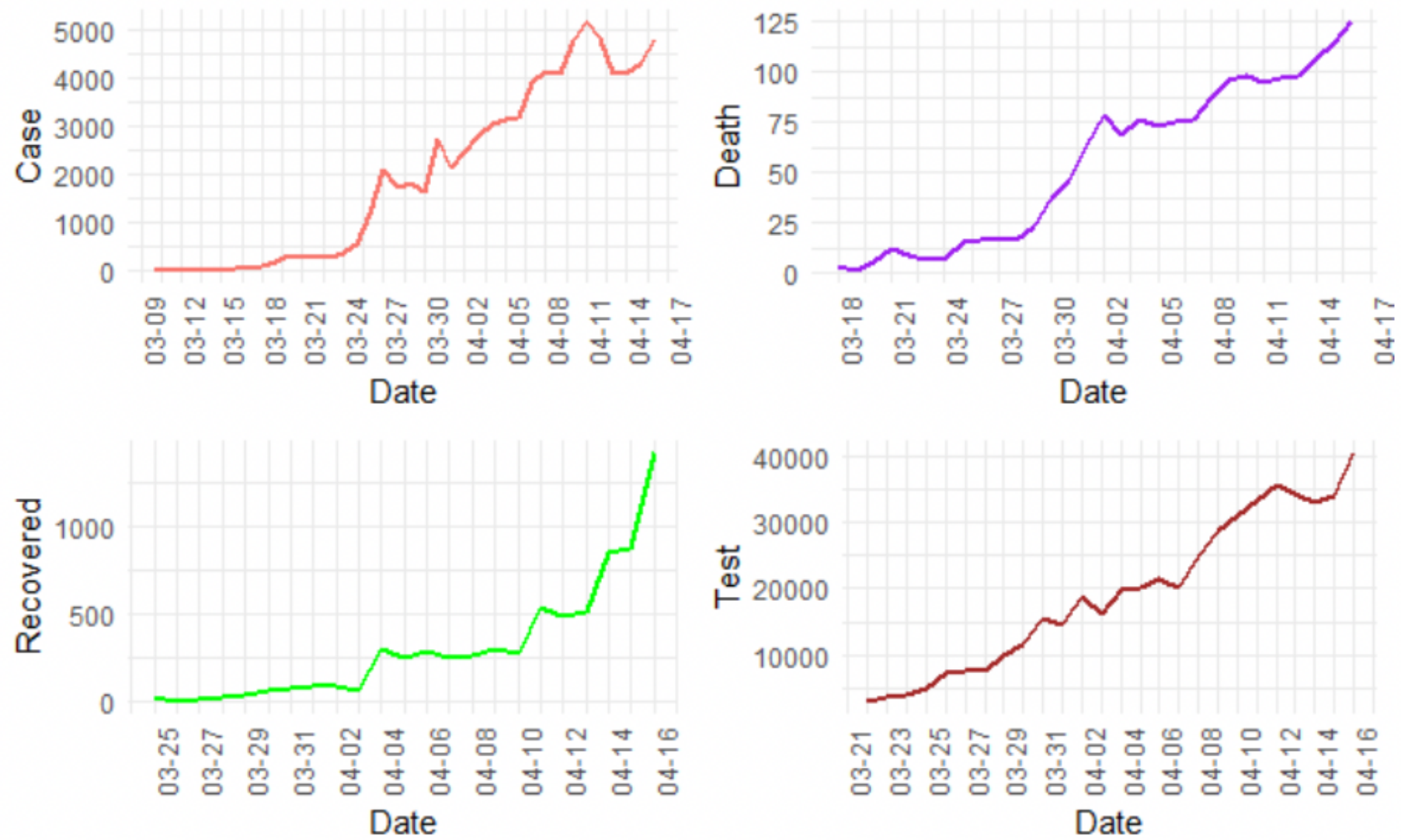

Figure 1

Number of Covid-19 Cases and Tests by Day in Turkey. Data Source: Republic of Turkey Ministry of Health 

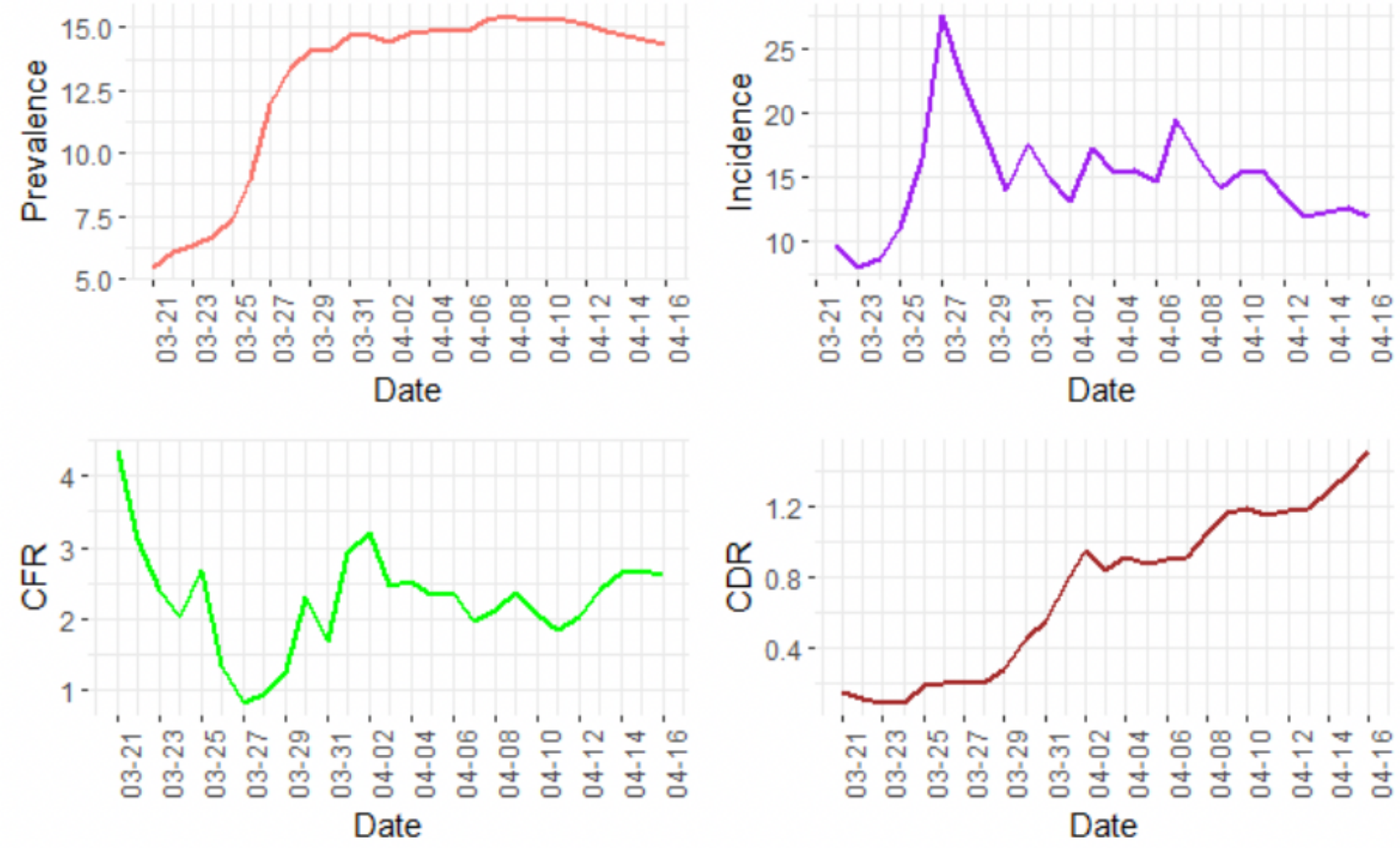

Figure 2

Epidemiological Rates of COVID-19 Cases by Day in Turkey. Data Source: Republic of Turkey Ministry of Health 


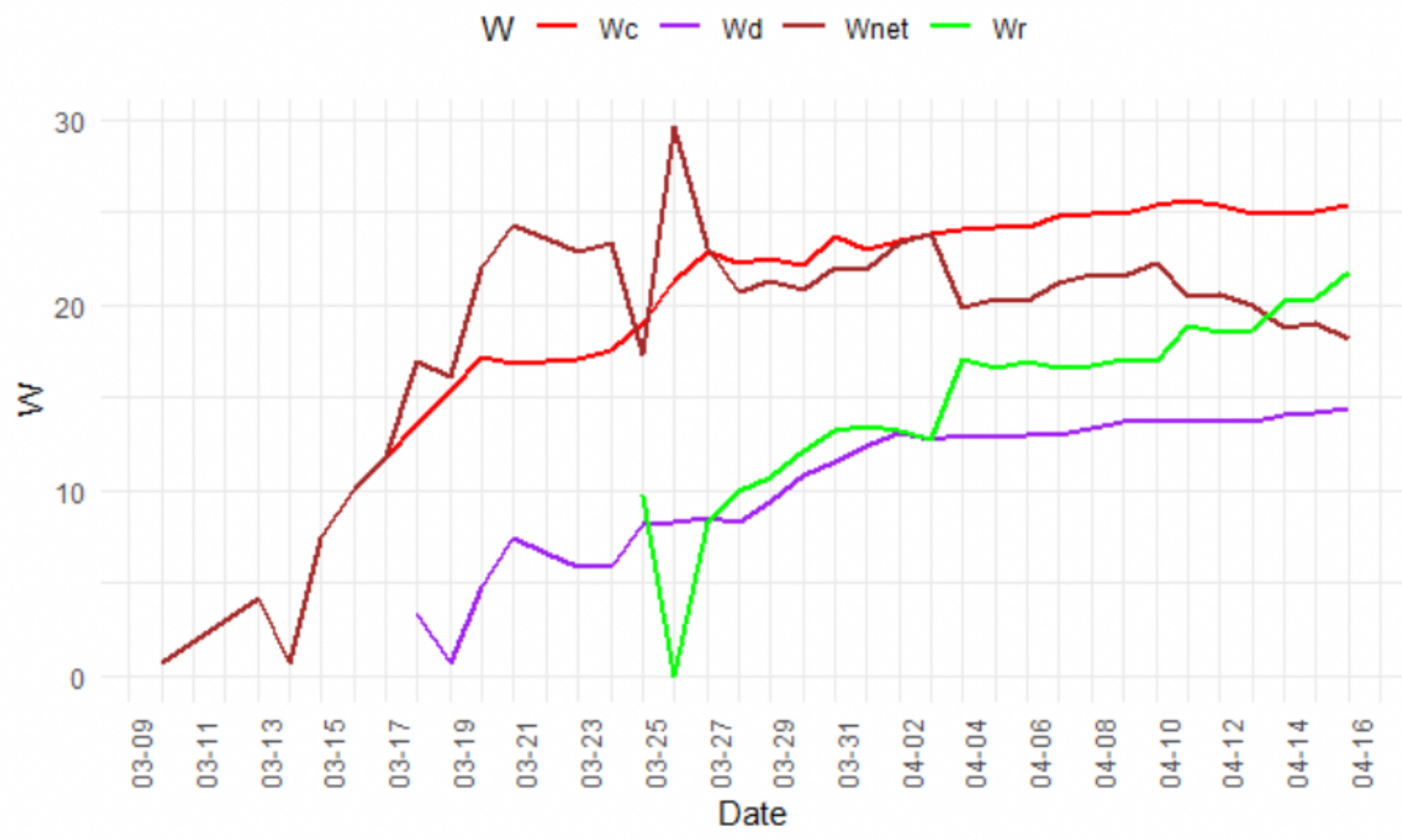

Figure 3

Daily Wavelengths in Turkey. Data Source: Republic of Turkey Ministry of Health 

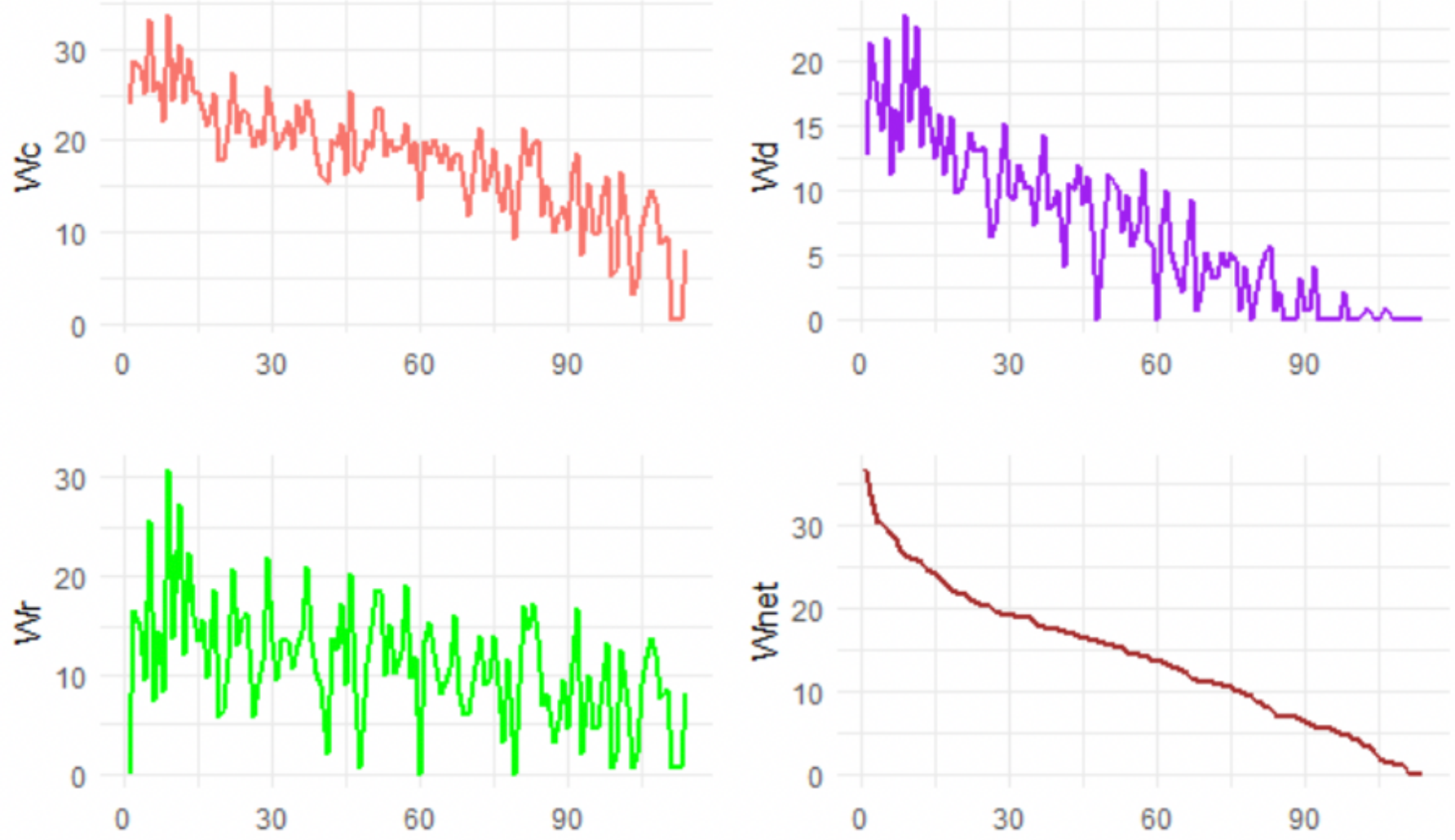

Figure 4

The First 36-Day Wavelengths in the World. Data Source: The Humanitarian Data Exchange (HDX) 

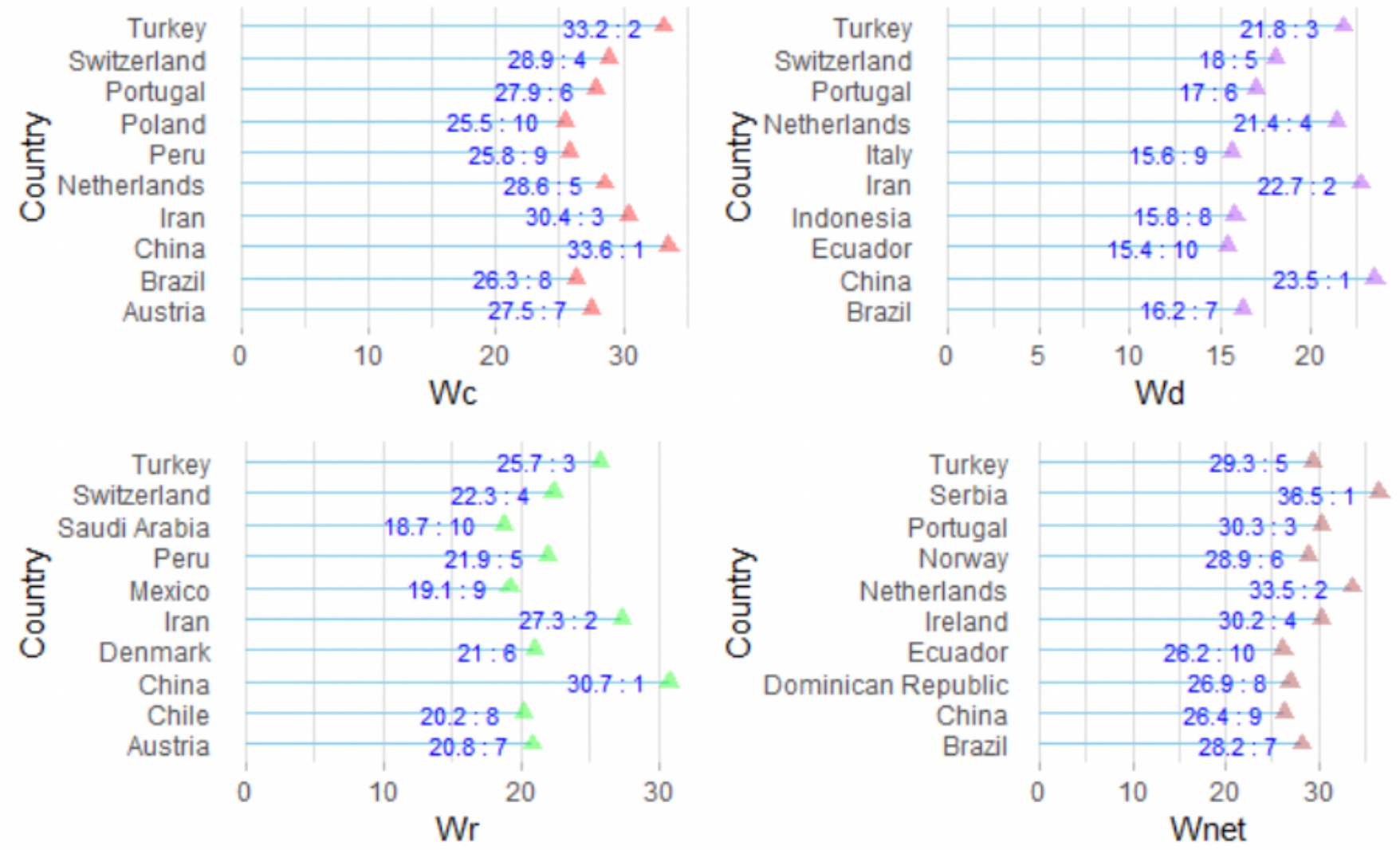

Figure 5

The First 36-Day Wavelengths by Countries. Data Source: The Humanitarian Data Exchange (HDX) 

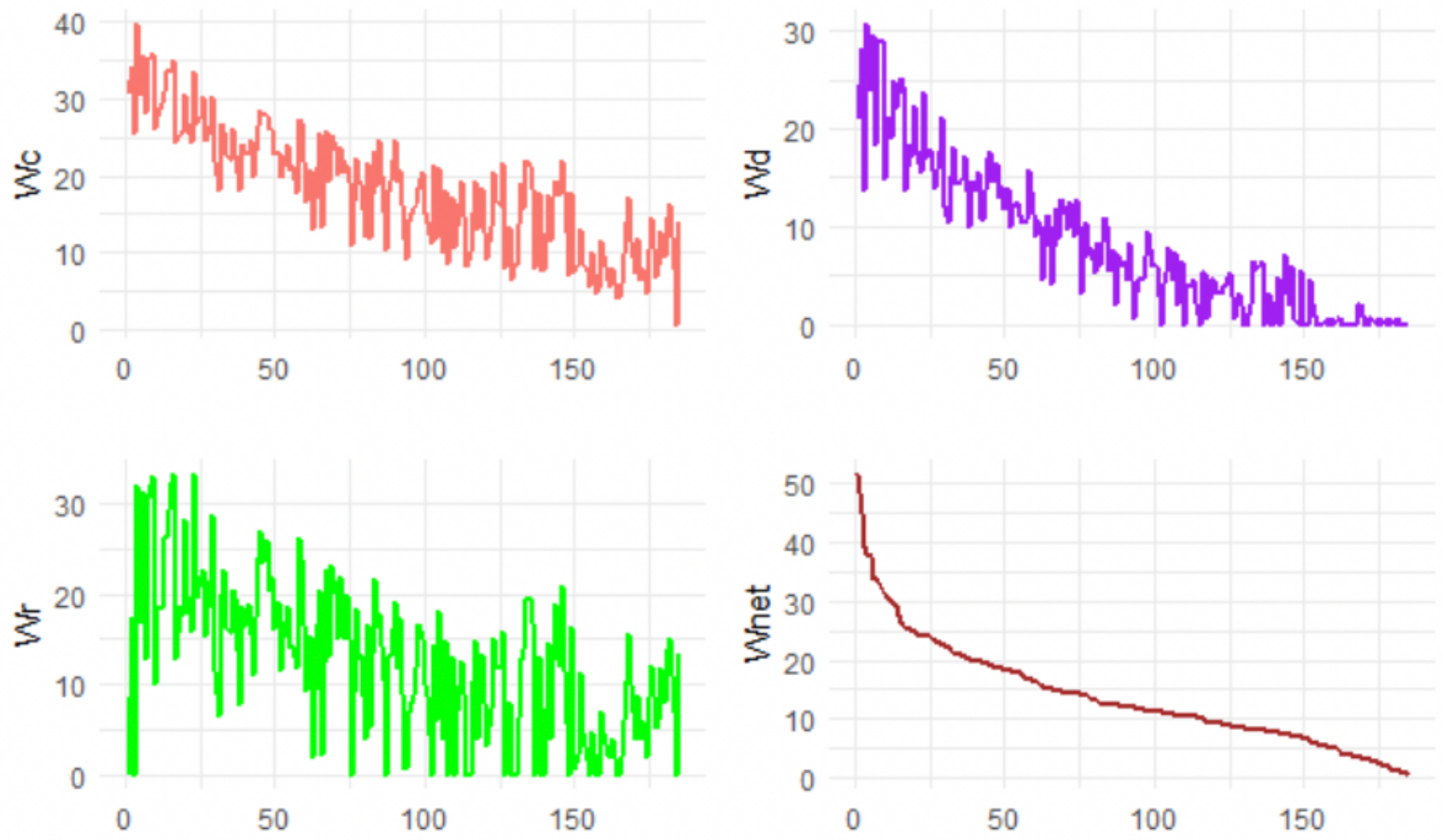

Figure 6

Wavelengths in the World on April 16, 2020. Data Source: The Humanitarian Data Exchange (HDX) 

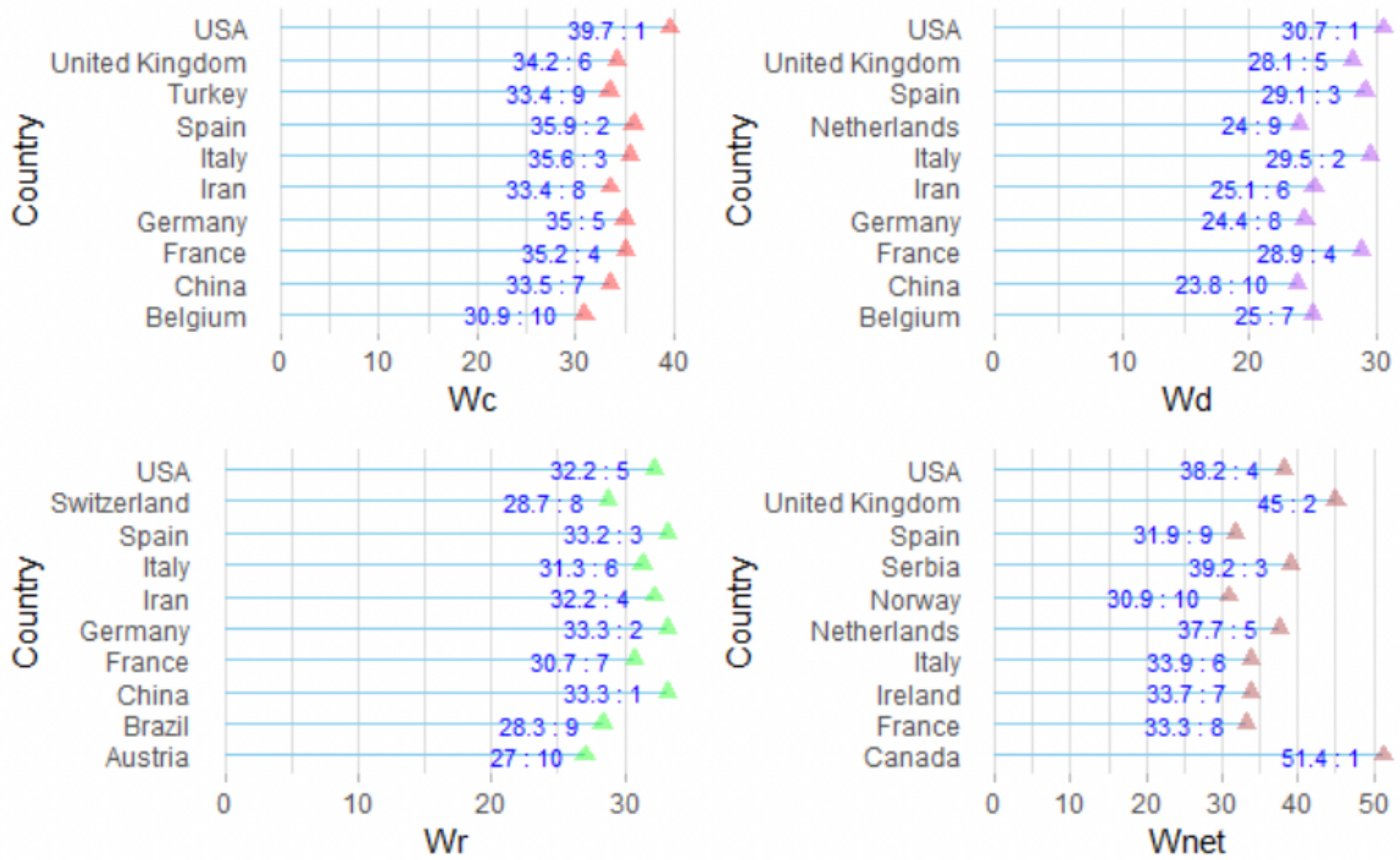

\section{Figure 7}

Wavelengths by Countries on April 16, 2020. Data Source: The Humanitarian Data Exchange (HDX)

\section{Supplementary Files}

This is a list of supplementary files associated with this preprint. Click to download.

- datasetday36countries.xlsx

- datasetfullofcountries.xlsx

- Turkeydata.xIsx 